\title{
Focal form of congenital hyperinsulinism clearly detectable by contrast-enhanced computed tomography imaging
}

\author{
Yukiko Hashimoto ${ }^{1 *}$, Azumi Sakakibara', Rie Kawakita', Yuki Hosokawa', Rika Fujimaru', Tetsuro Nakamura², \\ Hiroko Fukushima ${ }^{3}$, Aiko Igarashi ${ }^{4}$, Michiya Masue ${ }^{5}$, Hironori Nishibori ${ }^{5}$, Nobuyoshi Tamagawa $^{6}$, Akiko Murakami $^{6}$, \\ Kazue Hatake ${ }^{6}$ and Tohru Yorifuji, ${ }^{1,6}$
}

\begin{abstract}
The focal form of congenital hyperinsulinism (CHI) is characterized by a cluster of abnormal insulin-oversecreting $\beta$ cells within a restricted area of the pancreas. Although identification of the focal lesion is very important in the management of $\mathrm{CH}$, it has been reported that imaging studies, including computed tomography $(\mathrm{CT})$, magnetic resonance imaging (MRI) scans, or angiography, are not helpful in identifying the focal lesion. Currently, fluorine-18-L-dihydroxyphenylalanine positron emission tomography $\left({ }^{18} \mathrm{~F}-\mathrm{DOPA}\right.$ PET) is believed to be the only imaging modality that can identify the focal lesions. In this report, however, we present a case of a 7-month-old girl with the focal form of $\mathrm{CH}$, caused by a loss-of-function mutation in the $A B C C 8$ gene, whose lesion was clearly visible as a hyperenhancing nodule on contrast-enhanced CT and dynamic MRI imaging.
\end{abstract}

\section{Background}

Congenital hyperinsulinism (CHI) is the most common cause of persistent hypoglycemia in the neonatal/infantile period which often requires pancreatectomy when unresponsive to medical treatments [1-7].

There are two known histological forms of CHI: diffuse and focal. The focal form is characterized by a cluster of abnormal insulin-oversecreting $\beta$ cells within a restricted area of the pancreas, whereas in the diffuse form, abnormal $\beta$ cells are scattered throughout the pancreas. Focal $\mathrm{CHI}$ arises in individuals with a paternally inherited monoallelic mutation in one of the genes coding for pancreatic ATP-sensitive potassium channel ( $\mathrm{K}_{\text {ATP }}$ channel), KCNJ11 or $A B C C 8$, both located sideby-side in the chromosomal 11p15.1 region $[8,9]$. When a second event of paternal uniparental disomy at chromosome 11p15 occurs in a $\beta$ cell during the development of the pancreas, that particular cell loses the

\footnotetext{
* Correspondence: yukko930@gmail.com

'Department of Pediatric Endocrinology and Metabolism, Children's Medical Center, Osaka City General Hospital, 2-13-22 Miyakojima-hondori, Miyakojima, Osaka 534-0021, Japan

Full list of author information is available at the end of the article
}

$\mathrm{K}_{\mathrm{ATP}}$ channel activity, and also loses the activity of $\mathrm{H} 19$ and $C D K N 1 C$, which are adjacent imprinted tumor suppressor genes, expressed only from the maternal allele. Moreover, in $11 \mathrm{p} 15.5$, there is an oppositely imprinted growth factor gene, $I G F 2$, which is expressed only from the paternal allele. The gene dosage of IGF2 would be doubled when paternal uniparental disomy takes place. Consequently, the insulin-oversecreting abnormal $\beta$ cell acquires a growth advantage, eventually forming a focus of abnormal $\beta$ cells [10-12].

Since the focal form of $\mathrm{CHI}$ can be cured by partial pancreatectomy without postsurgical diabetes mellitus, when a patient is unresponsive to conservative therapy, identification of the focal lesion is very important. It has been reported that imaging studies, including computed tomography (CT), magnetic resonance imaging (MRI) scans, or angiography, are not helpful in identifying focal lesions, since they do not distort the surrounding normal pancreatic structure, and also lack significant vascularization $[13,14]$. Localization of the focal form, therefore, has been identified only by fluorine18-L-dihydroxyphenylalanine positron emission tomography $\left({ }^{18} \mathrm{~F}\right.$-DOPA PET) scans or by invasive diagnostic procedures such as arterial stimulation with venous 


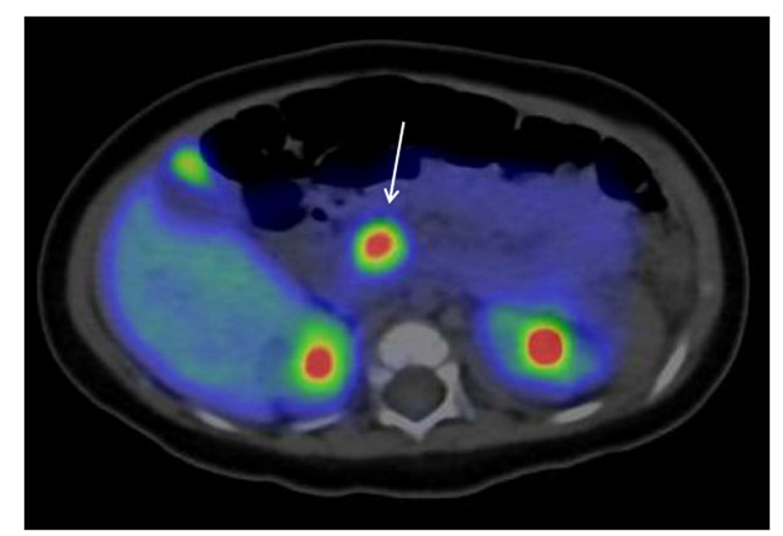

Fig. $1{ }^{18}$ F-DOPA PET scan. A focal lesion was identified in the head of the pancreas (arrow)

sampling (ASVS) or transhepatic portal venous sampling (THPVS) [15-17].

In this report, however, we present a case of a 7month-old girl with the focal form of $\mathrm{K}_{\mathrm{ATP}}$ channel $\mathrm{CHI}$ whose lesion was clearly visible as a hyperenhancing nodule on contrast-enhanced CT and dynamic MRI imaging corresponding to the site detected by ${ }^{18} \mathrm{~F}$-DOPA PET scan.

\section{Case presentation}

The patient was a 7-month-old Japanese girl who was born after 39 weeks of an uneventful pregnancy, with a birth weight of $3792 \mathrm{~g}$ (+2.4 standard deviation [SD]) and length $54 \mathrm{~cm}(+2.7 \mathrm{SD})$. Both parents were healthy and there was no family history of hypo- or hyperglycemia. On the second day of life, she presented with hypothermia associated with hypoglycemia. A diagnosis of hyperinsulinemic hypoglycemia was made, based on the characteristic findings at the time of hypoglycemia: plasma glucose $1.6 \mathrm{mmol} / \mathrm{L}$ with serum insulin $26.7 \mathrm{pmol} / \mathrm{L}$, undetectable ketone bodies, normal lactate, and normal ammonia. She was unresponsive to diazoxide at a dose of $20 \mathrm{mg} / \mathrm{kg} /$ day, and required $8.6 \mathrm{mg} / \mathrm{kg} / \mathrm{min}$ of intravenous glucose infusion to maintain normoglycemia. From the $15^{\text {th }}$ day of life, continuous subcutaneous octreotide infusion was started, and at $25 \mu \mathrm{g} / \mathrm{kg} /$ day of octreotide, glucose infusion could be stopped. However, hypoglycemic episodes persisted quite often despite frequent feedings. Fortunately, her psychosocial growth and psychomotor development remained within the normal range despite frequent hypoglycemic episodes.

Mutational analysis revealed that she had a paternally inherited monoallelic mutation in the ABCC8 gene (c.2506C > T, p.Arg836*). ${ }^{18}$ F-DOPA PET performed at 4 months of age revealed focal uptake in a single region in the head of the pancreas (Fig. 1). Based on these results, surgical resection of the focus was scheduled at 7 months of age. Since an enlargement in the head of the pancreas was suspected by preoperative abdominal ultrasound, further studies using other imaging modalities were performed. Unexpectedly, a contrast-enhanced CT scan revealed a clearly enhancing nodule at the head of the pancreas, corresponding to the site of the focus detected by the ${ }^{18}$ F-DOPA PET scan (Fig. 2). Dynamic MRI imaging also detected a hyperenhancing nodule on the arterial phase. On T1- and T2-weighted imaging, the nodule showed an isointense signal, compared with the surrounding pancreatic parenchyma.

On laparotomy, a firmer focal lesion, measuring about $9 \mathrm{~mm}$ in diameter, was visible in the head of the pancreas which could be easily resected (Fig. 3). Microscopically, the lesion contained hyperplastic islets separated by thin fibrovascular bands. The islets were adenoma-like, and some of the $\beta$ cells within the lesion had enlarged nuclei typical of the focal form of $\mathrm{CHI}$ (Fig. 4). Insulin immunostaining showed increased insulin producing $\beta$ cells within the lesion (Fig. 4). The islets in the surrounding pancreas were normal.

DNA was extracted from the abnormal islets obtained by laser microdissection. Sequencing analysis of the $A B C C 8$ gene revealed predominance of a mutated paternal allele from these abnormal islets, confirming the diagnosis of the focal form of $\mathrm{K}_{\mathrm{ATP}}$ channel CHI (Fig. 5).

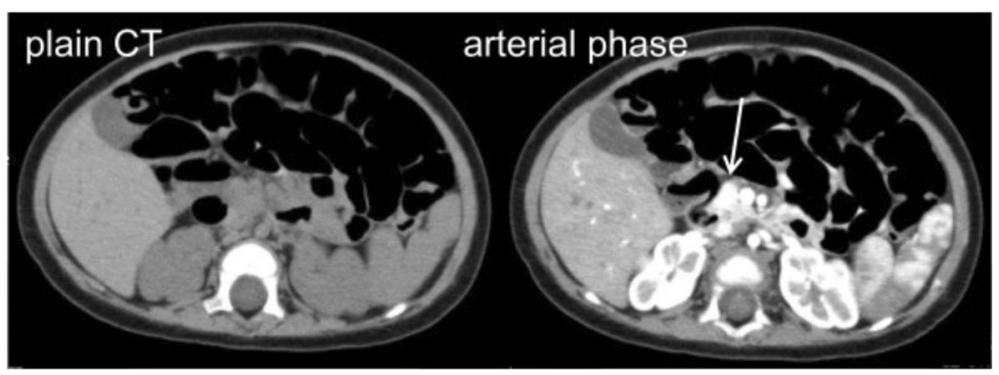

Fig. 2 CT scan. A hyperenhancing nodule was identified on the arterial phase 


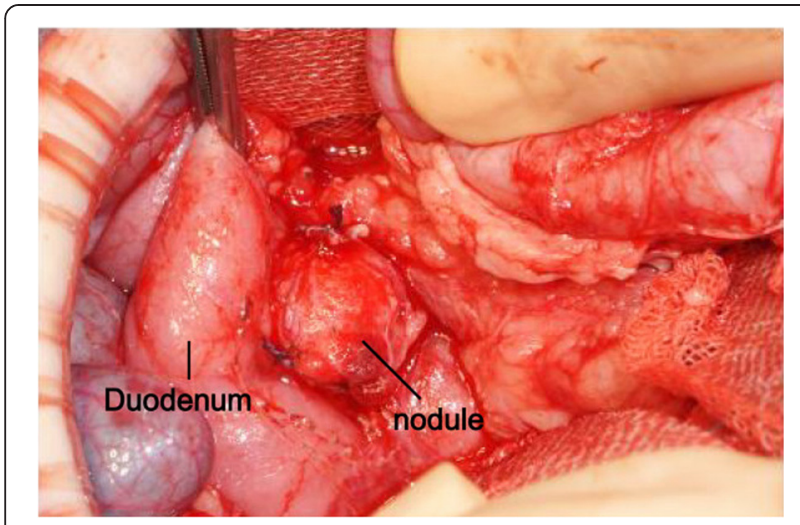

Fig. 3 Macroscopic finding of the focus. A nodule with a clear margin was identified in the head of the pancreas at laparotomy

\section{Molecular analysis}

Mutational analysis was performed as described previously [18]. Briefly, all exons and exon-intron boundaries of the $\mathrm{K}_{\text {ATP }}$ channel genes were amplified from genomic DNA and directly sequenced. Laser microdissection was performed using the Arcturus PIXCELL IIe (Life Technologies, Carlsbad, CA) instrument, as described in the manufacturer instructions. The study protocol was approved by the Institutional Review Board (No. 743), and written informed consent was obtained from the guardians of the patient.

\section{Discussion}

Contrary to the previous belief, our report shows that some of the focal $\mathrm{K}_{\mathrm{ATP}}$-channel $\mathrm{CHI}$ can be visualized by conventional imaging modalities such as contrastenhanced $\mathrm{CT}$ or dynamic MRI imaging. Although CT scans are not advisable for infants in view of the risk of irradiation, MRI imaging might be worth trying especially where ${ }^{18}$ F-DOPA PET scans are not easily available.

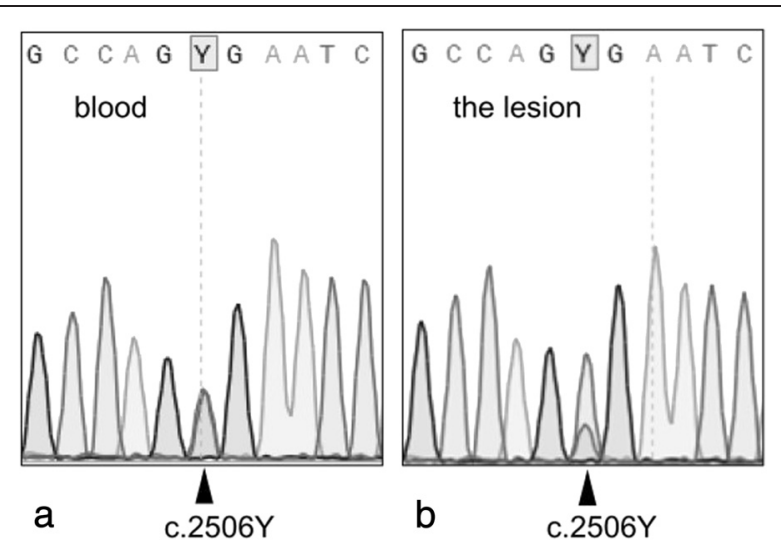

Fig. 5 Mutational analysis of the $A B C C 8$ gene. a DNA obtained from the peripheral blood leukocytes of the patient. A c.2506C > T mutation was detected in the heterozygous state with the wild type allele. The mutation was found to be of paternal origin (data not shown). b DNA obtained from the focus by laser microdissection. A loss of the wild type maternal allele was evident. The reduced peak of the wild type allele probably reflects the normal tissue within the focus

The reason why the focal lesion of our patient could be clearly visualized by contrast-enhanced CT and MRI scans is not clear. Generally, for pancreatic nodules to be visualized by these imaging modalities, they need to grow fast enough to have a mass effect. In addition, they need to have a higher vascularity, or higher vascular permeability, to be enhanced by the contrast media. The focal lesion of our patient somehow attained both of these properties. In contrast, the size and cell density of the lesion do not appear to be critical factors for visualization by these techniques $[19,20]$.

Since the tumor suppressor activity of our patient is presumed to be lost as in all other cases of focal $\mathrm{CHI}$, the higher growth potential of the focal lesion in this case might be explained by a difference in the growth promoting activity of the IGF2 gene, although no

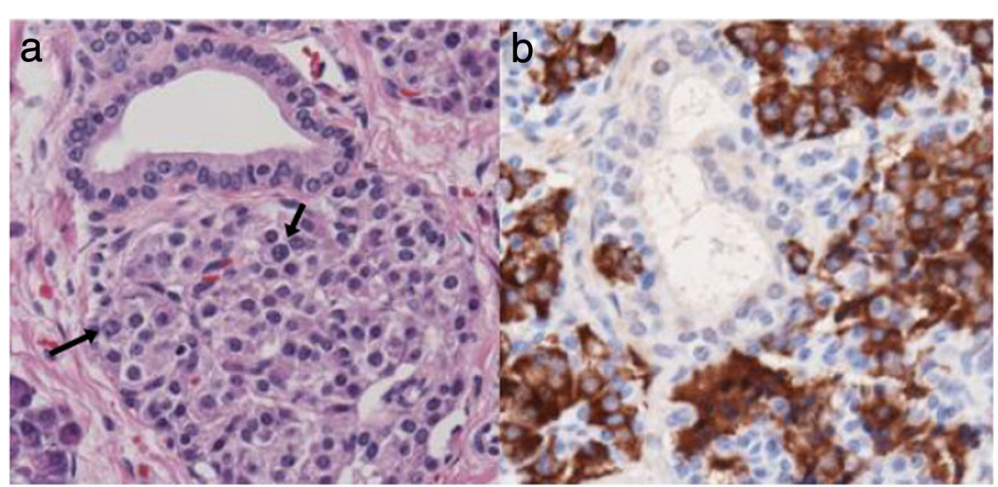

Fig. 4 Histological findings of the resected focus. a Hematoxylin eosin staining $(\times 400)$. Some of the $\beta$ cells within the lesion had enlarged nuclei (arrow). b Insulin staining $(\times 400)$. An increased number of insulin-positive $\beta$ cells were observed within the lesion 
mutations could be identified in the coding region of IGF2 in our patient (data not shown).

Microscopically, the vascularity in the focal lesion of our patient was not particularly different from that of other patients with the focal form of CHI. However, if the focal lesion has higher growth potential, capillary dilatation without angiogenesis could follow [21], which might explain the contrast enhancement observed in our patient.

\section{Conclusions}

We report the unprecedented findings in a case of a focal form of $\mathrm{CHI}$ whose lesion was clearly visible as a hyperenhancing nodule on contrast-enhanced CT and dynamic MRI imaging. The mechanism leading to the visualization of the focal lesion in our patient needs further investigation.

\section{Consent}

Written informed consent was obtained from the parents of the patient for publication of this Case Report and the accompanying images. A copy of the written consent is available for review by the Editor-in-Chief of this journal.

\section{Competing interests}

The authors declare that they have no competing interests.

\section{Authors' contributions}

Al first diagnosed the patient. YH took over the treatment and drafted the manuscript. TY was instrumental in coordinating this report and guides the genetic analysis on the patient. $\mathrm{KH}, \mathrm{NT}$, AM carried out the molecular genetic studies, and participated in the sequence alignment. TN and HF advised on interpreting the histological findings. MM and HN carried out the ${ }^{18} \mathrm{~F}$-DOPA PET scan and interpreted the result. AS, RK, YH and RF participated in the clinical care of the patient and revised the manuscript. All authors read and approved the final manuscript.

\section{Acknowledgements}

We thank the parents of the patient for participating in the study. This work was supported in part by a Grant-in-Aid for Scientific Research from the Ministry of Education, Culture, Sports, Science and Technology of Japan to TY (No. 15K09636).

\section{Author details}

'Department of Pediatric Endocrinology and Metabolism, Children's Medical Center, Osaka City General Hospital, 2-13-22 Miyakojima-hondori, Miyakojima, Osaka 534-0021, Japan. ${ }^{2}$ Department of Pediatric Surgery, Osaka City General Hospital, Osaka, Japan. ${ }^{3}$ Department of Pathology, Osaka City General Hospital, Osaka, Japan. ${ }^{4}$ Department of Pediatrics, Faculty of Medical Sciences, University of Fukui, Fukui, Japan. ${ }^{5}$ Department of Pediatrics, Kizawa Memorial Hospital, Chubu Medical Center for Prolonged Traumatic Brain Dysfunction, Minokamo, Japan. ${ }^{6}$ Clinical Research Center, Osaka City General Hospital, Osaka, Japan.

Received: 4 June 2015 Accepted: 14 August 2015 Published online: 15 September 2015

\section{References}

1. Menni F, de Lonlay P, Sevin C, Touati G, Peigne C, Barbier V, et al. Neurologic outcomes of 90 neonates and infants with persistent hyperinsulinemic hypoglycemia. Pediatrics. 2001;107:476-9.
2. Ludwig A, Ziegenhorn K, Empting S, Meissner T, Marquard J, Holl R, et al. Glucose metabolism and neurological outcome in congenital hyperinsulinism. Semin Pediatr Surg. 2011;20:45-9.

3. Yorifuji T. Congenital hyperinsulinism: current status and future perspectives Ann Pediatr Endocrinol Metab. 2014;19:57-68.

4. Hussain K. Diagnosis and management of hyperinsulinaemic hypoglycaemia of infancy. Hormone Res. 2008;69:2-13.

5. Mohamed Z, Arya VB, Hussain K. Hyperinsulinaemic hypoglycaemia:genetic mechanisms, diagnosis and management. J Clin Res Pediatr Endocrinol. 2012:4:169-81.

6. Banerjee I, Avatapalle B, Padidela R, Stevens A, Cosgrove KE, Clayton PE, et al. Integrating genetic and imaging investigations into the clinical management of congenital hyperinsulinism. Clin Endocrinol (Oxf). 2013;78:803-13.

7. Yorifuji T, Masue $M$, Nishibori $H$. Congenital hyperinsulinism: global and Japanese perspectives. Pediatr Int. 2014;56:467-76.

8. Kapoor RR, Flanagan SE, Arya VB, Shield JP, Ellard S. Clinical and molecular characterisation of 300 patients with congenital hyperinsulinism. Eur J Endocrinol. 2013;168:557-64.

9. Snider KE, Becker S, Boyajian L, Shyng SL, MacMullen C, Hughes N, et al. Genotype and phenotype correlations in 417 children with congenital hyperinsulinism. J Clin Endocrinol Metab. 2013;98:E355-63.

10. Rahier J, Guiot Y, Sempoux C. Persistent hyperinsulinaemic hypoglycaemia of infancy: a heterogeneous syndrome unrelated to nesidioblastosis. Arch Dis Child Fetal Neonatal Ed. 2000;82:F108-12.

11. Ismail D, Kapoor RR, Smith W, Ashworth M, Blankenstein O, Pierro A, et al. The heterogeneity of focal forms of congenital hyperinsulinism. J Clin Endocrinol Metab. 2012;97:E94-9.

12. Giurgea I, Sempoux C, Bellanne-Chantelot C, Ribeiro M, Hubert L, Boddaert N, et al. The Knudson's two-hit model and timing of somatic mutation may account for the phenotypic diversity of focal congenital hyperinsulinism. J Clin Endocrinol Metab. 2006;91:4118-23.

13. Meintjes M, Endozo R, Dickson J, Erlandsson K, Hussain K, Townsend C, et al. 18F-DOPA PET and enhanced CT imaging for congenital hyperinsulinism: initial UK experience from a technologist's perspective. Nucl Med Commun. 2010;34:601-8.

14. Ribeiro MJ, De Lonlay P, Delzescaux T, Boddaert N, Jaubert F, Bourgeois S, et al. Characterization of hyperinsulinism in infancy assessed with PET and 18F-fluoro-L-DOPA. J Nucl Med. 2005;46:560-6.

15. Barthlen W, Blankenstein O, Mau H, Koch M, Hohne C, Mohnike W, et al. Evaluation of [18F]fluoro-L-DOPA positron emission tomography-computed tomography for surgery in focal congenital hyperinsulinism. J Clin Endocrinol Metab. 2008:93:869-75.

16. Otonkoski T, Nanto-Salonen K, Seppanen M, Veijola R, Huopio H, Hussain K et al. Noninvasive diagnosis of focal hyperinsulinism of infancy with [18F]-DOPA positron emission tomography. Diabetes. 2006;55:13-8.

17. de Lonlay P, Simon-Carre A, Ribeiro MJ, Boddaert N, Giurgea I, Laborde K, et al. Congenital hyperinsulinism: pancreatic [18F]fluoro-L-dihydroxyphenylalanine (DOPA) positron emission tomography and immunohistochemistry study of DOPA decarboxylase and insulin secretion. J Clin Endocrinol Metab. 2006;91:933-40

18. Yorifuji T, Kawakita R, Nagai S, Sugimine A, Doi H, Nomura A, et al. Molecular and clinical analysis of Japanese patients with persistent congenital hyperinsulinism: predominance of paternally inherited monoallelic mutations in the KATP channel genes. J Clin Endocrinol Metab. 2011;96:E141-5.

19. Sempoux C, Guiot Y, Dahan K, Moulin P, Stevens M, Lambot V, et al. The focal form of persistent hyperinsulinemic hypoglycemia of infancy: morphological and molecular studies show structural and functional differences with insulinoma. Diabetes. 2003;52:784-94.

20. Filder JL, Fletcher JG, Reading CC, Andrews JC, Thompson GB, Grant CS, et al. Preoperative Detection of Pancreatic Insulinomas on Multiphasic Helical CT. Am J Roentgenol. 2003;181:775-80.

21. Dai C, Brissova M, Reinert RB, Nyman L, Liu EH, Thompson C, et al. Pancreatic islet vasculature adapts to insulin resistance through dilation and not angiogenesis. Diabetes. 2013;62:4144-53. 